УДК [811.161.2+811.111+811.112.2]:[164.2:159.937]

DOI https://doi.org/10.24919/2308-4863/41-1-25

\author{
Анастасія КІНАЩУК, \\ orcid.org/0000-0002-5675-240X
}

аспірантка кафедри романо-германської філології Рівненського державного гуманітарного університету (Рівне, Украӥна) nastia.kinash@gmail.com

\title{
АКТАНТИ ТЕМАТИЧНОЇ ГРУПИ ПРЕДИКАТІВ НА ПОЗНАЧЕННЯ ІРРАЦІОНАЛЬНОГО СПРИЙНЯТТЯ (НА МАТЕРІАЛІ УКРАЇНСЬКОЇ, АНГЛІЙСЬКОЇ ТА НІМЕЦЬКОЇ МОВ)
}

\begin{abstract}
У дослідженні розглянуто предикатно-актантні моделі, щзо представлені як один із способів презентувати семантичну структуру лексичних одиниць з позииї функиіонального синтаксису. У розвідиі досліджено тематичну групу предикатів на позначення ірраціонального сприйняття в українській, англійській та німецькій мовах. У статті описано иентральні елементи ядерної семантичної структури. У розвідиі уточнено поняття предиката й актанта з позииії функиіонального синтаксису. У дослідженні проаналізовано семантичні ролі учасників ірраціональної ситуації, серед яких виокремлено учасників Експерієнцер та Стимул. У статті схарактеризовано актанти Експерієнцер і Стимул відповідно до наведених прикладів в украйнській, англійській та німецькій мовах для досліджуваної тематичної групи предикатів у зіставному аспекті. Актанти Експерієнцер і Стимул проаналізовано відповідно до їхнього синтаксичного вираження, комунікативного рангу і таксономічного класу у семантичній структурі ірраціональної лексики української, англійської та німецької мов. Відзначено, щчо семантичні ролі учасників Експерієнцер і Стимул представлені у кожній з обраних мов. Визначено, щчо актанти Експерієнцер та Стимул відрізняються своїм синтаксичним вираженням (приналежністю до різних частин мов або поєднанням різних частин мов в одному словосполученні чи різними видами синтаксичного зв'язку у реченні), комунікативним рангом і таксономічним класом в украӥнській, англійській та німецькій мовах. Встановлено та проаналізовано особливості реалізації предикатно-актантних відношень для тематичної групи предикатів на позначення ірраціонального сприйняття у межах ірраціональної ситуації в українській, англійській та німецькій мовах. Визначено перспективи подальших досліджень семантичних структур ірраціональної лексики на предмет вивчення специифікаторів названої тематичної групи ірраціональних предикатів в украӥнській, англійській та німецькій мовах.

Ключові слова: предикатно-актантне моделювання, функиіональний синтаксис, семантична роль, синтаксична роль, синтаксичне вираження, комунікативний ранг, таксономічний клас.
\end{abstract}

\author{
Anastasiia KINASHCHUK, \\ orcid.org/0000-0002-5675-240X \\ Postgraduate student at the Department of Romance and Germanic Philology \\ Rivne State University for the Humanities \\ (Rivne,Ukraine)nastia.kinash@gmail.com
}

\section{ACTANTS OF THE THEMATIC GROUP OF PREDICATES TO DEFINE IRRATIONAL PERCEPTION (BASING ON THE UKRAINIAN, ENGLISH AND GERMAN LANGUAGES)}

The research deals with predicate-actant models that are interpreted as one of the means to present semantic structure of lexical units in the aspect of functional syntax. The study researches the thematic group of predicates to define irrational perception in the Ukrainian, English and German languages. It has been described central elements of the core semantic structure. The research specifies the notion of predicate and actant in the aspect of functional syntax. The paper analyzes semantic roles of the participants of irrational situation. The author singles out such participants as Experiencer and Stimulus. The study characterizes the actants Experiencer and Stimulus according to the given examples in the Ukrainian, English and German languages for researched thematic group of predicates in a comparative aspect. It has been analyzed actants Experiencer and Stimulus according to their syntactical expression, communicative rank and taxonomic class in semantic structure of irrational vocabulary in the Ukrainian, English and German languages in the comparative aspect. It is stated and analyzed specific characteristics of the implementation of predicate-actant relations for thematic group of predicates to define the irrational perception within the irrational situation in the Ukrainian, English and German languages. The paper defines following research of semantic structures of irrational vocabulary to analyze specifiers of the mentioned thematic group of irrational predicates in the Ukrainian, English and German languages.

Key words: predicate-actant modeling, functional syntax, semantic role, syntactical role, syntactical expression, communicative rank, taxonomic class. 
Постановка проблеми. Сьогоднішній етап розвитку лінгвістичної науки охоплює не лише когнітивний аспект дослідження мови, а й функціональний. У руслі функціонального синтаксису здійснювали свої розвідки іноземні (Ю. Апресян, О. Падучева) та вітчизняні (О. Деменчук) науковці. Зіставний аспект таких досліджень має на меті визначити подібності та відмінності у споріднених та неспоріднених мовах на предмет презентації особливостей світосприйняття представниками різних народів. Актуальність розвідки полягає в антропоцентричній тенденції мовознавчих досліджень споріднених та неспоріднених мов у сучасному мовознавстві.

Аналіз досліджень. До питання функціонального синтаксису у своїх напрацюваннях зверталися Н. Бондар (структурно-семантична характеристика речень 3 предикатами лексикосемантичної групи змін), О. Десюкевич (внутрішня і зовнішня семантика дієслів соціальних відносин), Т. Андрєєва (змістовий аспект предикативних відношень), А. Залізняк (дослідження предикатів внутрішнього стану), Р. Костіцина (класифікація дієслівних предикатів) та ін. У поле зору науковців потрапляли і специфічні лексикосемантичні групи, досліджувані у зіставному аспекті на матеріалі різних мов: предикати знання у російській, англійській та французькій мовах (Г. Аллагулова), позиційні предикати на матеріалі англійської та російської мов (О. Артемова), бестіальні дієслова російської та англійської мов у зіставно-типологічному та лексикографічному аспектах (О. Брагарник-Станкевич) та ін.

Напрацювання науковців цього напряму засвідчують актуальність розвідок 3 функціонального синтаксису не лише на предмет дослідження предикатів всередині однієї мови, а й у зіставному аспекті.

У розвідці представлено зіставний аналіз актантів предикатів тематичної групи на позначення ірраціонального сприйняття в українській, англійській та німецькій мовах. Об'єктом дослідження слугують предикати названої тематичної групи у зіставлюваних мовах, пор. : укр. маячити, видітися, фантазувати; англ daydream, hallucinate, fantasize; нім. erträumen, erscheinen, phantasieren, fantasieren.

Мета статті - схарактеризувати актанти тематичної групи предикатів ірраціонального сприйняття в українській, англійській та німецькій мовах.

Поставлена мета досягається через розв'язання таких конкретних завдань:

- уточнити поняття предиката та актантів 3 позиції функціонального синтаксису;
- схарактеризувати актанти досліджуваної тематичної групи предикатів у зіставному аспекті;

- описати особливості предикатно-актантних відношень ірраціональних предикатів у досліджуваних мовах;

- визначити перспективи подальших досліджень ірраціональної лексики.

Предмет та об'єкт дослідження. Предметом дослідження є предикатно-актантні відношення тематичної групи предикатів ірраціонального сприйняття в українській, англійській та німецькій мовах. Об'єктом дослідження слугували дібрані методом суцільної вибірки 16 дієслів (5 3 української мови, 5 з англійської мови, 6 з німецької), що належать до семантичного класу ірраціональної лексики.

Основними у дослідженні обрано описовий, зіставний методи та метод моделювання. Описовий метод уможливлює систематизацію та узагальнення зібраної інформації і фактичного матеріалу. За допомогою зіставного методу проаналізовано специфіку представлення предикатноактантних відношень в українській, англійській та німецькій мовах. Для формування предикатноактантних моделей застосовано метод моделювання. Сукупність вказаних методів забезпечують достовірність висновків та об'єктивність отриманих результатів.

Виклад основного матеріалу. Опис моделі функціонального синтаксису складається 3 певних семантичних структур, що презентують стан справ і коментарі того, хто говорить про цей стан справ. Складовими моделі функціонального синтаксису, за А. Мустайокі, є ядро семантичної структури, яке у свою чергу складається 3 предиката і актанта (Мустайокі, 2006: 412).

У розвідці предикат тлумачимо як логічну складову висловлювання, що наділена істинним значенням цього висловлювання та визначає відношення суб'єкта 3 іншими складовими семантичної структури. Разом із предикатами у дослідженні представлений й аналіз актантів, які трактуємо як таких учасників ситуації, що заповнюють валентність предиката за певною семантичною роллю та вступають у відповідні цій ролі відношення 3 предикатом. Для тематичної групи предикатів на позначення ірраціонального сприйняття основними є учасники Експерієнцер та Стимул. Під Експерієнцером розуміємо такого учасника ситуації, який сприймає певну інформацію та у певний спосіб опрацьовує іii, пор. : укр. I Лимареві марилося, щуо його тіло стає легесеньким $i$ він уже не пливе по водi, а пурхає в повітрі (10); англ. If we daydream while going through the motions 
Кінащук А. Актанти тематичної групи предикатів на позначення ірраціонального сприйняття...

of reading we can still recognise words, and perhaps (20); нім. Kredenzt mir wein, auf das berauscht wie Hafis ich phantasie wild von deiner schönheit (16). Учасника Стимул представлений різними типами інтелектуальних об’єктів, пор. : укр. Лучче б $m u$, сину, був зогнив у божевільні, куди тебе засадили розумні люди, що передбачали все че страхіття (10); англ. More difficult illusions require the subject to hallucinate objects or people into or out of existence with his eyes open (20); нім. Im "Traumstück» fantasiert sich der gereifte Dichter in allerhand Bilder unserer aufgewühlten Zeit hinein (16). Характеризуємо кожну із семантичних ролей ситуації, послуговуючись відповідними прикладами.

В українській мові у ситуації «ірраціональне сприйняття» актант Експерієнцер займає позицію підмета або прямого додатка: укр. Всі иі причепки редактора я передбачив, знаючи його погляди на газету і відносини до мене (14). Синтаксично Експерієнцер може бути виражений:

- іменником: укр. Колись Мумі (ие один приятель батька) постійно марилася пожежа (10);

- особовим займенником: укр. Йому лишень походи маряться (10).

За комунікативним рангом Експерієнцер належить до Центру уваги. Цього учасника ситуації характеризуємо за такими таксономічними класами:

- ЛЮДИНА: укр. Син того панства, пан Ваилав, часто заглядав до Солецьких, $і$ люди передбачали, щчо иче закінчиться маріяшом [шлюбом] (14);

- ТВАРИНА: укр. Отже свій виступ перед шановною аудиторією я почну з того, щуо нагадаю досить банальну істину: тварина, керована здебільшого інстинктом, майже не передбачає майбутнього (10).

В англійській мові у ситуації «ірраціональне сприйняття» учасник ситуації Експерієнцер також займає позицію підмета: англ. Sylvia had started to hallucinate, seeing creepy-crawlies on her bed, and the houseman had to come and sort her out (20). Синтаксично такий учасник може бути виражений:

- іменником: англ. Yes, people did foresee this pandemic happening (15);

- особовим займенником: англ. She wondered if she really could hallucinate a walking, talking nightmare. It couldn't really be him (20).

За комунікативним рангом Експерієнцер належить до Центру уваги. Цього учасника ситуації характеризуємо за такими таксономічними класами:

- ЛЮДИНА: англ. Look, may - maybe I did hallucinate the phone call (18);
- ЧАСТИНА ТІЛА: англ. The old hands were less excited and settled down to daydream the time away until supper (20).

У німецькій мові у ситуації «ірраціональне сприйняття» актант Експерієнцер також займає позицію підмета: нім. Kredenzt mir wein, auf das berauscht wie Hafis ich phantasie wild von deiner schönheit (16).Синтаксично Експерієнцер може бути виражений:

- іменником: нім. Etwa eine Frau, die im Kopf ständig von einem Schauspieler fantasiert (17);

- означеним та неозначеним артиклем: нім. Der eine phantasierte sich in seinen Romanen zum omnipotenten Helden und betrog Generationen von Lesern, der andere ist gleich Casanova der Inbegriff leibhaftiger Omnipotenz, der viele Menschen seiner Zeit um Gut und Leben betrog (16);

- особовим займенником: нім. ...wir endlich sehen, schauen, denken, erinnern, phantasiren oder glauben (16);

- неозначено-особовим займенником: нім. Man soll ja nicht über sich spintisieren, und daß an mir kein übermäßig großes Talent verlorengegangen ist (19).

За комунікативним рангом учасник Експерієнцер належить до Центру уваги. Учасника Експерієнцер характеризуємо за такими таксономічними класами:

- ЛЮДИНА: нім. In einer anderen Schule wäre dabei schwerlich etwas Brauchbares herausgekommen; die Sechsjährigen fantasierten munter und gar nicht töricht darauflos, und bewiesen, in welcher Art hier bei Gaudig die kleinsten Geister zum Arbeiten vorgebildet wurden (16).

В українській мові у ситуації «ірраціональне сприйняття» учасник Стимул займає або позицію прямого додатка, або підмета: укр. ...він незбагненним чином міг зазирати в чужі душі й передбачати подї близького майбутнього (10); А Яремкові все виділася далека Ганя (10). Синтаксично такий учасник ситуації може бути виражений:

- іменником: укр. Передбачив зміни [автор.];

- неозначеним займенником: укр. Може, щось подібне марилося мені тоді, коли я втікав зі Львова (10);

- 3'ясувальною підрядною частиною зі сполучниками щзо та як: I Лимареві марилося, щео його тіло стає легесеньким і він уже не пливе по водi, а пурхає в повітрі (10); Травіаті мариться, як досхочу їсть диню (10);

- безсполучниковою частиною: укр. Так вона й передбачала - сприймуть як чирковий номер (10). 
За комунікативним рангом актант Стимул належить до Центру уваги. Такого учасника ситуації характеризуємо за такими таксономічними класами:

- ПОДІЯ: укр. ...коли він незбагненним чином міг зазирати в чужі душі й передбачати подіi близького майбутнього (10);

- ДІЯ: Погано без годинника: ијілу ніч мариться, щео пора вставати (10);

- ОБРАЗ: укр. Маячили в уяві образи якоїсь чудної природи та життя, сум погаслого дня, тихих міст з білими тужно-пустельними стінами (10);

- АРТЕФАКТ: укр. Згадався вчорашній сон рік від року однаково мариться купальський під льодом вінок, щяо б'ється, шукаючи ополонку, волошки й рум'янок вплетені між вербових гілок, мляво хилитаються течією, «напевно, від матері лист надійде (10);

- ТВАРИНА: укр. А радше йому просто марилася потворна істота, зображена на килимі у верхівиі «піраміди мертвих» (10).

В англійській мові у ситуації «ірраціональне сприйняття» Стимул займає позицію прямого додатка: англ. She wondered if she really could hallucinate a walking, talking nightmare. It couldn't really be him (20). Синтаксично такий учасник може бути виражений:

- іменником: англ. англ. The old hands were less excited and settled down to daydream the time away until supper (20).

За комунікативним рангом актант Стимул належить до Центру уваги. Цього учасника ситуації характеризуємо за такими таксономічними класами:

- ОБРАЗ: англ. She wondered if she really could hallucinate a walking, talking nightmare. It couldn't really be him (20);

- ЛЮДИНА: англ. Luke Parker has been feeding Elena some concoction that allows her to hallucinate Damon (18);

- ДІЯ: англ. Look, may - maybe I did hallucinate the phone call (18);

- ЧАС: англ. The old hands were less excited and settled down to daydream the time away until supper (20);

- ПОДІЯ: англ. Almost everyone would like to have more money and many people daydream of being millionaires (20).

У німецькій мові у ситуації «ірраціональне сприйняття» учасник Стимул займає позицію прямого додатка: нім. Die Eltern fantasierten ihre Kinder als engelhafte Unschuldswesen (21). Синтаксично такий актант може бути виражений:
- іменником: нім. Die ganze Nacht über hätte ich irre phantasiert - von "Einsatzkräften» und «erhöhter Wachsamkeit»(16);

- підрядною означальною частиною: нім. Und wenn Sie das feststellen, werden Sie darüber phantasieren, daß früher die Preise stimmten und die Politiker integer waren (22);

- часткою $d a$ та відповідним прийменником: нім. Im Innersten denkt sie anders (als sie einmal zusammenbricht, fantasiert sie davon), doch infolge ihrer Pflegeabhängigkeit gibt es keine Möglichkeit, aus dem «Kindspielen» auszubrechen (16);

- сполученням прийменника та займенника: нім. An seiner Drehbank phantasierte er von ihr, erinnerte er sich der mit ihr verlebten Stunden und fieberte neuen entgegen (16).

За комунікативним рангом учасник Стимул належить до Центру уваги. Актанта Стимул характеризуємо за такими таксономічними класами:

- ЛЮДИНА: нім. Glaubst du vielleicht, was ein doofer Schwärmer von dir phantasiert? (16);

- ПОДІЯ: нім. Und wenn Sie das feststellen, werden Sie darüber phantasieren, daß früher die Preise stimmten und die Politiker integer waren (16);

- ОБРАЗ: нім. Kredenzt mir wein, auf das berauscht wie Hafis ich phantasie wild von deiner schönheit (16);

- TBIP: нiм. Ich wendete mich an die Nibelungen..ich..fand die Stelle, wo die Meerfrauen dem kühnen Helden weissagen..ich phantasirte mir. eine für sich bestehende Ballade..die mich in der Einbildungskraft oft beschäftigte, obschon ich es nicht dazu brachte sie abzuschließen (16).

Висновки та перспективи подальших пошуків. Таким чином, у розвідці уточнено поняття предиката (як складової, що визначає відношення суб'єкта 3 іншими складовими семантичної структури) та актанта (учасник, що заповнює валентність предиката за певною семантичною роллю). В українській, англійській та німецькій мовах предикатно-актантні моделі тематичної групи предикатів на позначення ситуації «ірраціональне сприйняття» презентують учасників Експерієнцер та Стимул. Предикатноактантні відношення досліджуваної тематичної групи засвідчують явище ірраціональності як таке, що виявляється як певний інтелектуальний об'єкт (Стимул), який сприймає учасник Експерієнцер.

Перспективи подальших розвідок на предмет дослідження ірраціональної лексики вбачаємо у зіставному вивченні специфікаторів для досліджуваної тематичної групи предикатів в українській, англійській та німецькій мовах. 


\section{СПИСОК ВИКОРИСТАНИХ ДЖЕРЕЛ}

1. Аллагулова Г. Р. Предикаты знания в русском, английском и французском языках: дис. ...канд. филол. наук: 10.02.19. Уфа, 2004. 216 с.

2. Андреева T. H. Содержательный аспект предикативных отношений. URL: https://elib.bsu.by/bitstream/123456789/256635/1/55-58.pdf.

3. Апресян Ю. Д. Фундаментальная классификация предикатов и системная лексикография. URL: https://iling.spb.ru/typo/materials/gc03pdf/apresjan_spb2003.pdf.

4. Артемова О. А. Позиционные предикаты в английском и русском языках: сравнительно-сопоставительный аспект. URL: https://www.alba-translating.ru/ru/ru/articles/2015/artemova-o-a.html.

5. Бондарь Н. О. Структурно-семантическая характеристика предложений с предикатами лексико-семантической группы глаголов изменения: автореф. ... дис. канд. филол. наук: 10.02.01. Киев, 1990. 27 с.

6. Брагарник-Станкевич О. С. Бестиальные глаголы русского и английского языков: сопоставительно-типологический и лексикографический аспекты : автореф. дис. ... канд. филол. наук : 10.02.20. Минск, 2017. 29 с.

7. Деменчук О. В. Динамічні моделі перцептивної лексики (на матеріалі української, польської та англійської мов). Філологічні студії. 2014. Випуск 11. С. 39-46.

8. Десюкевич О. И. Внутренняя и внешняя семантика глаголов социальных отношений (на материале русских глаголов победы и поражения). Acta Universitatis Lodziensis. 2019. № 18. С. 71-83.

9. Зализняк А. А. Исследования по семантике предикатов внутреннего состояния. Мюнхен: Verlag Otto, 1992. $203 \mathrm{c}$.

10. Корпус української мови. URL: http://www.mova.info/corpus.aspx.

11. Костицина Р. В. К вопросу о классификации глагольных предикатов. URL: https://cyberleninka.ru/article/n/kvoprosu-o-klassifikatsii-glagolnyh-predikatov.

12. Мустайоки А. Теория функционального синтаксиса. Москва: Языки славянской культуры. 2006. 512 с.

13. Падучева Е. В. Динамические модели в семантике лексики. Москва: Языки славянской культуры, 2004. 608 с.

14. Словник української мови. URL: http://sum.in.ua/.

15. Dale D. Yes, people did foresee this pandemic happening. URL: https://www.mercurynews.com/2020/03/16/analysis-yes-people-did-foresee-this-pandemic-happening/.

16. Digitales Wörterbucher der Deutschen Sprache. URL: https://www.dwds.de/

17. Huber S. Die Fantasie darf nicht der Masstab sein für die Realität. URL: https://www.schweizer-illustrierte.ch/people/swiss-stars/die-fantasie-darf-nicht-der-massstab-sein-fur-die-realitat.

18. Reverso.Context. URL: https://context.reverso.net.

19. Tausende Träumen von diesem Mann: Wer ist er? URL: https://www.merkur.de/multimedia/tausende-traeumen-diesem-mann-zr-505007.html.

20. The British National Corpus. Electronic resource: https:/www.english-corpora.org/bnc/ .

21. Die deutsche Rechtschreibung. URL: https://www.duden.de/.

22. Wörterbuchnetz.URL: http://www.woerterbuchnetz.de/.

\section{REFERENCES}

1. Allagulova G. R. Predikaty znanija v russkom, anglijskom i francuzskom jazykah: dis. ...kand. filol. nauk: 10.02 .19 [Predicates of knowledge in the Russian, English and French languages: thesis ...for cand. of philol. sciences: 10.02.19], Ufa, 2004, 216 c. [in Russian].

2. Andreeva T. N. Soderzhatel'nyj aspekt predikativnyh otnoshenij [Content aspect of predicates' relations], URL: https://elib.bsu.by/bitstream/123456789/256635/1/55-58.pdf [in Russian]

3. Apresjan Ju. D. Fundamental'naja klassifikacija predikatov i sistemnaja leksikografija [Fundamental classification of predicates and system lexicography], URL: https://iling.spb.ru/typo/materials/gc03pdf/apresjan_spb2003.pdf [in Russian].

4. Artemova O. A. Pozicionnye predikaty v anglijskom i russkom jazykah: sravnitel'no-sopostavitel'nyj aspect [Positional predicates in the English and Russian languages: comparative aspect], URL: https://www.alba-translating.ru/ru/ ru/articles/2015/artemova-o-a.html [in Russian].

5. Bondar' N. O. Strukturno-semanticheskaja harakteristika predlozhenij s predikatami leksiko-semanticheskoj gruppy glagolov izmenenija: avtoref. ... dis. kand. filol. nauk: 10.02.01, Kiev, 1990, 27 s. [in Russian].

6. Bragarnik-Stankevich O. S. Bestial'nye glagoly russkogo i anglijskogo jazykov: sopostavitel'no-tipologicheskij i leksikograficheskij aspekty : avtoref. dis. ... kand. filol. nauk : 10.02.20 [Bestial verbs of the Russian and English languages: comparative and typological and lexicographical aspects: abstract of thesis for cand. of philol. sciences: 10.02.20], Minsk, 2017, 29 s. [in Russian].

7. Demenchuk O. V. Dynamichni modeli pertseptyvnoi leksyky (na materiali ukrainskoi, polskoi ta anhliiskoi mov) [Dynamic models of perceptive vocabulary (basing on the Ukrainian, Polish and English languages)], Filolohichni studii, 2014, Vypusk 11, S. 39-46 [in Ukrainian].

8. Desjukevich O. I. Vnutrennjaja i vneshnjaja semantika glagolov social'nyh otnoshenij (na materiale russkih glagolov pobedy i porazhenija) [Internal and external semantics of the verbs of social relations (basing on Russian verbs of the victory and lose)], Acta Universitatis Lodziensis, 2019, № 18, S. 71-83 [in Russian].

9. Zaliznjak A. A. Issledovanija po semantike predikatov vnutrennego sostojanija [Research in semantics of predicates of inner state], Mjunhen: Verlag Otto, 1992, 203 c. [in Russian].

10. Korpus ukrainskoi movy [The Ukrainian language corpus], URL: http://www.mova.info/corpus.aspx [in Ukrainian]. 
11. Kosticina R. V. K voprosu o klassifikacii glagol'nyh predikatov [More on a classification of verb predicates], URL: https://cyberleninka.ru/article/n/k-voprosu-o-klassifikatsii-glagolnyh-predikatov [in Russian].

12. Mustajoki A. Teorija funkcinal'nogo sintaksisa [Theory of functional syntax], Moskva: Jazyki slavjanskoj kul'tury, 2006, 512 s. [in Russian].

13. Paducheva E. V. Dinamicheskie modeli v semantike leksiki [Dynamic models in vocabulary semantics], Moskva: Jazyki slavjanskoj kul'tury, 2004, 608 s. [in Russian].

14. Clovnyk ukrainskoi movy [Dictionary of the Ukrainian language], URL: http://sum.in.ua/ [in Ukrainian].

15. Dale D. Yes, people did foresee this pandemic happening, URL: https://www.mercurynews.com/2020/03/16/analysis-yes-people-did-foresee-this-pandemic-happening/ man].

16. Digitales Wörterbucher der Deutschen Sprache [German language dictionary] URL: https://www.dwds.de/ [in Ger-

17. Huber S. Die Fantasie darf nicht der Masstab sein für die Realität [Fantasy should not be the yardstick for reality] URL: https://www.schweizer-illustrierte.ch/people/swiss-stars/die-fantasie-darf-nicht-der-massstab-sein-fur-die-realitat [in German].

18. Reverso. Context, URL: https://context.reverso.net

19. Tausende Träumen von diesem Mann: Wer ist er? [Thousands of dreams about this man: who is he?] URL: https://www.merkur.de/multimedia/tausende-traeumen-diesem-mann-zr-505007.html [in German].

20. The British National Corpus. Electronic resource: https://www.english-corpora.org/bnc/

21. Die deutsche Rechtschreibung [The German spelling] URL: https://www.duden.de/ [in German].

22. Wörterbuchnetz [Dictionary network] URL: http://www.woerterbuchnetz.de/ [in German]. 